\title{
An update on the chemistry, pharmacology and dose calcula- tions of mepivacaine hydrochloride for podiatrists in the United Kingdom
}

\author{
Ian Reilly ${ }^{1,2}$, Nicola Burt ${ }^{1}$, Rebecca Reilly ${ }^{3}$ and Ajay Swami ${ }^{2}$ \\ 1 Department of Podiatric Surgery, Northamptonshire Healthcare Foundation NHS Trust \\ 2 Private Practice, Ramsay Woodlands Hospital \\ 3 Harrogate District Hospital, Harrogate \\ Corresponding author: ianreilly@nhs.net. Danetre Hospital, Daventry, Northamptonshire, NN11 4DY. UK
}

\begin{abstract}
Background: Local anaesthetic agents suppress action potentials in excitable tissues by blocking voltage-gated sodium channels. In doing so they inhibit the depolarisation of nociceptive nerve fibres and so prevent the transmission of pain impulses. UK legislation allows HCPC-registered Podiatrists with POM-A annotation access to six local anaesthetic drugs and two of these with the addition of adrenaline. The use of local anaesthesia has transformed the treatment of nail pathology by Podiatrists. (2) Methods: a narrative review followed a comprehensive literature search. (3) Results: In the UK, the drug of choice in podiatric practice is 3\% mepivacaine hydrochloride: it is a good choice of drug for digital anaesthesia. (4) Conclusion: This paper will review the chemistry, pharmacology and dose calculation of mepivacaine, and challenge some of the orthodoxy over the rigid calculation of maximum safe dosages..
\end{abstract}

Keywords: Mepivacaine, Scandonest, local anaesthesia, pharmacology, podiatry, maximum safe dose.

\section{Introduction}

Local anaesthesia (LA) is defined as any technique that renders part of the body insensitive to pain or sensation without affecting consciousness (Khan, 2017). LA drugs do this by interrupting neural conduction via the inhibition sodium ion influx through ionophores within neuronal membranes (Malamed, 2019). Their key application is to facilitate pain free treatment (Pope and Brown, 2020). Clinical experience and pharmacological discoveries have allowed the development of safe and efficient practice using a range of different drugs since Halstead's first peripheral nerve block in 1885 (Calatayud, 2003). The history of LA is a fascinating subject in its own right. For those that want to know more about the origins and advancement of this branch of medicine, refer to the chapter by Chuan and Harrop-Griffiths in Hadzic's Textbook of Regional Anesthesia and Acute Pain Management (Chuan and Harrop-Griffiths, 2017), and work by Borthwick (Borthwick, 2001/05) who details the Podiatric history of access to these drugs.

UK legislation allows registered podiatrists with Health and Care Professions Council (HCPC) POM-A annotation (POM-A annotation replaced the 'LA Certificate' in 2016 see table 1) access to six amino-amide LA drugs, and two of these with the addition of adrenaline (HMRs, 2012). LA use has transformed podiatric practice over the last 60 years, with most infiltrations (outside of the sub-group of UK Podiatric Surgeons) being given as a digital block prior to nail surgery (Maher, 2020). Lidocaine hydrochloride is the most widely used anaesthetic in medicine and dentistry worldwide (Becker, 2012) but mepivacaine hydrochloride (M.HCl) appears to be the most commonly used agent in UK podiatric practice ( ${ }^{*}$ based on the senior author's experience of teaching under- and postgraduate LA theory and practice). 
The aim of this paper is to give podiatric colleagues an update on the chemistry and pharmacology of $\mathrm{M} . \mathrm{HCl}$, to give an overview of the variability in dose calculations and to challenge some of the orthodoxy over the rigid calculation of maximum safe dosages. It will be provided as a preprint to obtain wider professional feedback before the next iteration of this work.

\begin{tabular}{|l|l|l|}
\hline Persons exempted & Prescription only medicines to which the exemption applies & Conditions \\
\hline $\begin{array}{l}\text { 1. Registered } \\
\text { chiropodists or }\end{array}$ & 1. Prescription only medicines for parenteral administration that contain - & 1. \\
podiatrists against & (a) Adrenaline, & The \\
whose names are & (c) Bupivacaine hydrochloride, & administration shall \\
only be in the course \\
recorded in the & adrenaline does not exceed $1 \mathrm{mg}$ in $200 \mathrm{ml}$ of bupivacaine hydrochloride, & of their professional \\
relevant register & (d) Levobupivacaine hydrochloride, & practice and where \\
annotations & (e) Lidocaine hydrochloride, & the medicine includes \\
signifying that they & (f) Lidocaine hydrochloride with adrenaline where the maximum strength of & a combination of \\
are qualified to use & adrenaline does not exceed $1 \mathrm{mg}$ in 200 ml of lignocaine hydrochloride, & substances in column \\
the medicines & (g) Mepivacaine hydrochloride, & 2 , those substances \\
specified in column & (h) Methylprednisolone, & shall not have been \\
2. & (i) Prilocaine hydrochloride, & combined by the \\
& (j) Ropivacaine hydrochloride. & chiropodist or \\
podiatrist.
\end{tabular}

Table 1: The Human Medicines Regulations 2012, Schedule 17, Part 3

\section{Materials and Methods}

For this review, a strategy that involved searching for research evidence via three different sources was adopted:

- Electronic databases - healthcare databases advanced search (HDAS)

- Reference lists

- Google scholar

HDAS allowed access to the following databases, which were considered the give the best chance of identifying appropriate sources:

- AMED (Allied and Complementary Medicine: 1985 - present)

- CINHAL (Cumulative Index to Nursing and Allied Health Lit.: 1981 - present)

- EMBASE (Excerpta Medica Database: 1974 - present)

- MEDLINE (Medical Literature Analysis and Retrieval Online: 1946 - present)

Additionally, NYSORA (New York School of Regional Anaesthesia), the Cochrane Database of Systematic Reviews, the Royal Society of Medicine and hand searches of the Journal of Foot and Ankle Surgery, the Journal of Foot and Ankle Research were searched. Keywords used were: mepivacaine, toxicity, podiatr*, (with searches limited to humans) with Boolean operators AND and OR for: dose, local anaesthesia, anaesthesia, maximum safe dose, and/or history. Truncation was with $n=*[2](+/-1)$ were additional to the latter keywords as to avoid omitting corresponding articles. Inclusion criteria or selected articles were:

- Mepivacaine (or Scandonest)

- Maximum safe dose (MSD) or calculations used in local anaesthesia

- Systemic toxicity of mepivacaine in both adults and children 
Exclusion criteria were those of studies involving general anaesthesia, studies involving analgesia outside the podiatric field (though some dental articles were of use), studies specific to other LA involvement, and studies transcribed and translated from languages other than English.

\section{Review}

\section{Histology and Physiology of Action Potentials}

The sodium-potassium pump is an electrogenic transmembrane ATPase structure that pumps three sodium ions out of the cell and two potassium ions into the cell, for every single ATP consumed (Pirahanchi et al, 2020). The voltage-gated sodium channel sits across the cell membrane. It is a complex structure composed of a pore-forming protein made up from an alpha subunit and beta subunits. The alpha subunit is comprised of four domains, each containing six segments that wrap round to form a bell-shaped central channel. The channel itself is formed by the S5 and S6 segments and the short loops of amino acids that link them (Taylor and McLeod, 2019).

First described by Hodgkin and Huxley (Hodgkin and Huxley, 1952), three conformational states of the channel exist: resting, open, and inactivated. The membrane potential is approximately $-70 \mathrm{mV}$ in the resting state: this charge is generated by the movement of positively charged potassium ions from outside the neuron (to the inside) via the sodium-potassium pump and the negatively charged anions that remain within the cell (Taylor and McLeod, 2019). After a stimulus, the sodium channels open during depolarisation, allowing a rapid influx of sodium ions down the electrical and chemical gradient which leads to channel inactivation. Impulse generation along a nerve causes rapid movement of sodium ions inwards and potassium ions outwards. An action potential is generated when the membrane potential increases to a threshold of $-55 \mathrm{mV}$. Thereafter, the sodium/potassium pump restores the excitable state of the resting membrane potential (Malamed, 2019).

\section{Chemistry and Pharmacology of Local Anaesthetics}

The local anaesthetic molecule consists of 3 components: a lipophilic aromatic ring, an intermediate ester or amide chain, and a terminal hydrophilic amine (Columb and MacLennan, 2007; Taylor and McLeod, 2019). Each of these contribute distinct properties to the molecule (see fig 1). The intermediate linkage provides a basis for classification and also determines the pattern of biotransformation: amino-esters are hydrolysed by plasma esterases, whereas amino-amides are bio transformed hepatically. The terminal amine may exist in a lipid-soluble tertiary form (3 bonds) or as a positively charged, watersoluble quaternary form (4 bonds) (Becker, 2006).

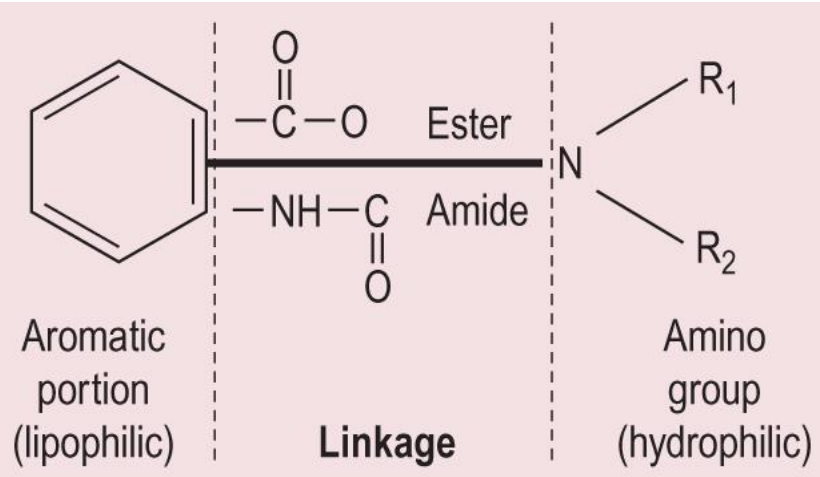

Figure 1: basic structure a local anaesthetic (Metcalfe and Reilly, 2010) 
For the local anaesthetic base to be stable in solution, it is formulated as a (watersoluble) hydrochloride (acid) salt. This is represented by:

$\mathrm{B}$ (base LA) + H+ (hydrochloride salt) $\leftrightharpoons \mathrm{BH}+($ protonated form $)$

Following the diffusion of the non-ionised base through the neural (cell) membrane into the axoplasm, it re-protonates and enters the voltage-gated sodium channels to suppress action potentials by inhibiting the influx of sodium ions, preventing the ion channel from assuming an active or "open" state (Becker, 2006; Taylor and McLeod, 2019). The quaternary form of a LA will not penetrate the neuron and therefore the time for onset of anaesthesia is predicated on the proportion of molecules that convert to the tertiary, lipidsoluble structure when exposed to physiologic pH (7.4) (Becker 2006).

The pKa of a molecule represents the $\mathrm{pH}$ at which $50 \%$ of the molecules exist in the tertiary, lipid-soluble form and 50\% in the quaternary, water-soluble form. The Henderson-Hasselbalch equation ( $\mathrm{Log}$ [non-ionized drug]/[ionized drug] $=\mathrm{pH}-\mathrm{pKa}$ ) allows us to calculate the ratio of those two states (Tsuchiya, 2007). The acidic environment of inflamed tissues favours the quaternary, water-soluble configuration and accounts for difficulty in anesthetising inflamed or infected tissues as fewer molecules exist as tertiary lipid-soluble form that penetrates nerves. In these situations, $\mathrm{M} . \mathrm{HCl}$ with pKa of 7.6 (this $\mathrm{pH}$ value varies in different sources) - compared to bupivacaine with a pKa of 8.1 - is more likely to provide effective anaesthesia (Becker, 2006).

The aromatic ring improves the lipid solubility of the compound. Greater lipid solubility enhances diffusion through nerve sheaths and neural membranes: this correlates with drug potency because a greater portion of an administered dose can enter neurons (Becker, 2006). Circulating LA is bound by plasma proteins ( $\alpha 1$-acid glycoproteins). The duration of action of each LA agent depends on plasma protein binding and correlates with a compound's affinity for the protein of the sodium channels. Bupivacaine exhibits $95 \%$ protein binding compared to $55 \%$ or $77 \%$ (references vary) for $\mathrm{M} . \mathrm{HCl}$, hence the difference in their duration of neural blockade (Becker, 2012). Both potency and duration of action also correlate with increasing molecular weight but also with an increased onset time and potential for severe systemic toxicity (Butterworth, 2017). The duration of action can also be affected by:

- Individual response to the drug

- Accuracy in deposition of the drug

- Status of tissues at the site of drug deposition (vascularity, $\mathrm{pH}$ )

- Anatomic variation

- Type of injection administered (field or nerve block)

- Addition of a vasoconstrictor (Malamad, 2019)

The addition of a vasoconstrictor, such as epinephrine (adrenaline) prolongs the anaesthetic effect by reducing the systemic distribution of the agent. Multiple sources state that vasoconstrictors must not be used to produce ring-block of an extremity (e.g. a finger or toe) because they may cause prolonged ischaemia and gangrene (Broomhead, 2020). The senior author regularly adds $2 \%$ lidocaine with 1/200,000 epinephrine to long acting LA agents such as levo-bupivacaine and ropivacaine for peripheral nerve blocks. This is interesting topic and worthy of a further commentary in another paper (spoiler alert: the risks are likely exaggerated). The chapter by Broomhead (2002), in the most up to date general podiatric text, has outline on all the common amino-amides available to podiatrists apart from $\mathrm{M} . \mathrm{HCl}$. 
Amino amides are metabolised by phase I and II hepatic cytochrome P450. Through phase I, hydroxylation, N-dealkylation and methylation occurs. Phase II includes conjugation with amino acids such as glycine (Columb and MacLennan, 2007).

\section{Mepivacaine}

In 1956 and 1957, Af Ekenstam et al developed, and later discussed, mepivacaine and bupivacaine (and others) (Af Ekenstam et al., 1956; Af Ekenstam et al., 1957), the former being the subject of this review. Mepivacaine is a white, crystalline, poorly soluble, odourless powder, with a melting point $1510 \mathrm{C}$ and a molecular weight and $246.4 \mathrm{Da}$; 2610C/285.5 Da as the readily soluble mepivacaine hydrochloride (Gordon, 1960). Its properties are summarised in table 2. This is a summary from product monographs, Patient Information Leaflets (PILs, e.g., www.drugs.com) and Summary of Product Characteristics (SPCs) found through the literature search. As noted below, the primary evidence source is often missing or unclear in such documentation. PILs and product data are supported by the pharmaceutical industry. In communication with the Chief Executive Officer of one of these companies, it was stated that these guidelines are for educational purposes only and are not intended for medical advice, diagnosis and treatment (unreferenced on request).

\begin{tabular}{|c|c|}
\hline Chemistry & $\begin{array}{l}\text { Mepivacaine was the second amide local anaesthetic to be clinically introduced. } \\
\mathrm{C}_{15} \mathrm{H}_{22} \mathrm{~N}_{2} \mathrm{O} . \mathrm{HCl} \text { : 1-methyl-2', 6'-pipecoloxylidide monohydrochloride is a tertiary amide salt. } \\
\text { The hydrochloride is easily soluble in water, stable in solution, very resistant to acid and alkaline } \\
\text { hydrolysis, and can be repeatedly boiled without decomposition. }\end{array}$ \\
\hline Brand names & Scandonest (UK), Carbocaine (US) \\
\hline Available concentrations & $1 \%, 1.5 \%, 2 \%$ with epinephrine $1: 100,000,3 \%$ solutions \\
\hline Dose $\mathrm{mg} / \mathrm{kg}$ and total & $\begin{array}{l}\text { Adults: } 4.4,5,6 \text {, or } 6.6 \text { (varies on the reference) } \\
\text { The MSD for healthy adults should not exceed } 400 \mathrm{mg} \text { at one treatment } \\
\text { Children } 3 \text { or } 5 / 6 \text { (varies on the reference) } \\
\text { Concentrations of less than } 2 \% \text { for those under } 3 \text { years of age }\end{array}$ \\
\hline Onset time & Medium (10) minutes \\
\hline $\mathrm{pH} / \mathrm{pKa}$ & 4.5 to 6.8 / 7.6 or 7.7 (varies on the reference) \\
\hline Onset time & Medium (10) minutes \\
\hline Duration of anaesthesia & Medium (120-180) minutes \\
\hline Peak plasma levels & $10-20$ minutes \\
\hline Relative toxicity & Low (0.77) \\
\hline Potency & Medium \\
\hline Mean half-life & $1-2$ hours \\
\hline Protein binding & 55 or $77 \%$ (varies on the reference) \\
\hline $\begin{array}{l}\text { Contra-indications and } \\
\text { precautions }\end{array}$ & $\begin{array}{l}\text { Mepivacaine has been shown to be less toxic (systemic and neural tissue) than lidocaine in adults } \\
\text { and provides a somewhat longer duration of action than lidocaine because of a less pronounced } \\
\text { vasodilatory effect. Injection of repeated doses of mepivacaine may cause significant increase in } \\
\text { blood levels with each repeated dose due to slow accumulation of the drug or its metabolites, or } \\
\text { due to slower metabolic degradation than normal. Tolerance varies with the status of the patient. }\end{array}$ \\
\hline
\end{tabular}


Debilitated, elderly patients, acutely ill patients, and children should be given reduced doses commensurate with their weight and physical status.

Mepivacaine should be used with caution in patients with a history of severe disturbances of cardiac rhythm or heart block. Young children should be given minimal doses of each agent. Changes in sensorium such as excitation, disorientation, drowsiness, may be early indications of a high blood level of the drug and may occur following inadvertent intravascular administration or rapid absorption of mepivacaine.

Mepivacaine is contraindicated in patients with a known hypersensitivity to amide-type local anaesthetics. The binding affinity of mepivacaine in serum is reduced in the presence of bupivacaine. Displacement of mepivacaine by bupivacaine was observed when an $\alpha 1$ acid glycoprotein solution was studied via classic competitive inhibition. Allergic-type reactions are rare and may occur as a result of sensitivity to the local anaesthetic or to other formulation ingredients. These reactions are characterized by signs such as urticaria, pruritus, erythema, angioneurotic oedema (including laryngeal oedema), tachycardia, sneezing, nausea, vomiting, dizziness, syncope, excessive sweating, elevated temperature, and possibly, anaphylactic-like symptoms (including severe hypotension). Patients allergic to methylparaben or para aminobenzoic acid derivatives (procaine, tetracaine, benzocaine, etc. have not shown crosssensitivity to amino-amides agents.

Mepivacaine crosses the placenta: there is considerable transfer of mepivacaine across the placenta after maternal doses and the ratio of foetal to maternal concentrations is about 0.7. Although neonates have a very limited capacity to metabolise mepivacaine it appears they are able to eliminate the drug. On the basis of long usage, anaesthetics of the mepivacaine type are considered to be reasonably safe for use on pregnant women.

Retrospective studies of pregnant women receiving local anaesthetics for emergency surgery early in pregnancy have not shown that local anaesthetics cause birth defects. However, no controlled studies have been carried out in pregnant women. Moreover, no animal reproduction studies have been performed with mepivacaine. Therefore, caution should be taken before administering this anaesthetic during early pregnancy. The mutagenic potential of mepivacaine has not been evaluated. It is not known whether local anaesthetics are excreted in human milk. Because many drugs are excreted in human milk, caution should be exercised when mepivacaine is administered to a nursing woman.

Drug interactions https://www.drugs.com/drug-interactions/mepivacaine.html

https://www.medicinescomplete.com/\#/content/bnf/ 390463595 interactions.

Table 2: M.HCl Summary - Metcalfe and Reilly, 2010; Multrum, 2020, and PILs/SPCs

$\mathrm{M} . \mathrm{HCl}$ is available in various percentages for dental, epidural and peripheral nerve blockade (Fenten et al, 2015; Lopez et al, 2015; Maladad, 2019). After deposition of the drug as close to the nerve as possible, the solution diffuses three-dimensionally according to prevailing concentration gradients. A portion of the injected local anaesthetic diffuses into the nerve. $\mathrm{M} . \mathrm{HCl}$ is rapidly metabolized, with only a small percentage of the anaesthetic (5-10\%) being excreted unchanged in the urine. Because of its amide structure it is not detoxified by the circulating plasma esterases; the liver is the principal site of metabolism with over $50 \%$ of the administered dose being excreted into the bile as metabolites. Most of the metabolized mepivacaine is resorbed in the intestine and then excreted into 
the urine since only a small percentage is found in the faeces. The principal route of excretion is via the kidney (Brockmann, 2013; Meffin, 1973).

Systemic adverse reactions involving the central nervous system (CNS) and the cardiovascular system (CVS) usually result from high plasma levels due to excessive dosage, rapid absorption, or inadvertent intravascular injection. Reactions involving the CNS are characterized by excitation and/or depression. Nervousness, dizziness, blurred vision, or tremors may occur followed by drowsiness, convulsions, unconsciousness, and possibly respiratory arrest. Since excitement may be transient or absent, the first manifestations may be drowsiness merging into unconsciousness and respiratory arrest. (Septodont, 2009).

A small number of reactions may result from hypersensitivity or diminished tolerance to normal dosage on the part of the patient. Allery to mepivacaine, though rare, has been reported (Diaz, 1975; Hiyoshi, 1978; Falace and Hill, 1985; Gonzalez-Delgado et al, 2006; Venemalm et al, 2008; Estrada et al, 2011; Sharma, 2013). Such reactions are characterized by cutaneous lesions of delayed onset or urticaria, oedema and other manifestations of allergy.

\section{Maximum Safe Dose}

As with all medications and drug use, a full medical history needs be obtained prior to deliverance to provide safe and effective administration as to avoid systemic toxicity and adverse drug reactions (ADRs) (Kihm, 2011; Columb and MacLennan, 2007; Rosenberg, 2004). The safety and effectiveness of mepivacaine depend upon proper dosage, correct technique, adequate precautions, and readiness for emergencies. The lowest dose that results in effective anaesthesia should be used to avoid high plasma levels and possible adverse effects. The adverse effects of LA may be:

- $\quad$ Local (e.g. transient neurologic syndrome or local trauma)

- $\quad$ Regional (e.g. hypotension after extensive neuraxial block)

- Systemic, after accidental intravenous injection or cumulative overdose (Reynolds, 2005):

For any given LA agent, the dose given is equal to the volume of drug given multiplied by its concentration:

Dose $(\mathrm{mg})=$ volume $(\mathrm{ml}) \times$ concentration $(\mathrm{mg} / \mathrm{ml}-1)$

A pharmacological maximum safe dose (MSD) is the largest dose of a medicine or drug consistent with safety: one thought to have an acceptable risk:benefit profile (Merriam-Webster, 2020). Maximum amounts were originally recommended as endpoint values, for example 200mg of lidocaine plain (incidentally this is much lower than in the US where the MSD is $300 \mathrm{mg}$ ) but manufacturer package inserts now also include LA dose recommendations that take the patient's body mass into consideration (Kihm, 2011) - often without reference to an original source (Columb and MacLennan, 2007; Rosenberg, 2004). Much of evidence for MSD and toxicity is based on extrapolation from animal studies and case reports rather than from higher level evidence from clinical trials (Moore et al., 1977; De Jong, 1994).

UK Podiatry departments often produce local guidelines to direct and support clinical practice. Such protocols may include such statements as:

"When administering local anaesthesia, the weight and maximum safe dosage must be calculated and recorded on the nail surgery treatment record using the following to assist: adult maximum safe dose is $400 \mathrm{mg}$ (i.e. $6.5 \times 2.2 \mathrm{ml}$ cartridges) or $6 \mathrm{mg} / \mathrm{kg}$ in 24 
hours. $3 \%$ solution contains $30 \mathrm{mgs} / \mathrm{ml}$ therefore $13.3 \mathrm{ml}$ of $3 \%$ solution $=400 \mathrm{mg}$ " (Torbay and South Devon NHS Foundation Trust, 2017).

$6.5 \times 2.2 \mathrm{ml}$ cartridges would in fact give a total dose of $429 \mathrm{mg}$, but, in practice, it is almost impossible to expel all the solution via a dental syringe (see fig 2 ).

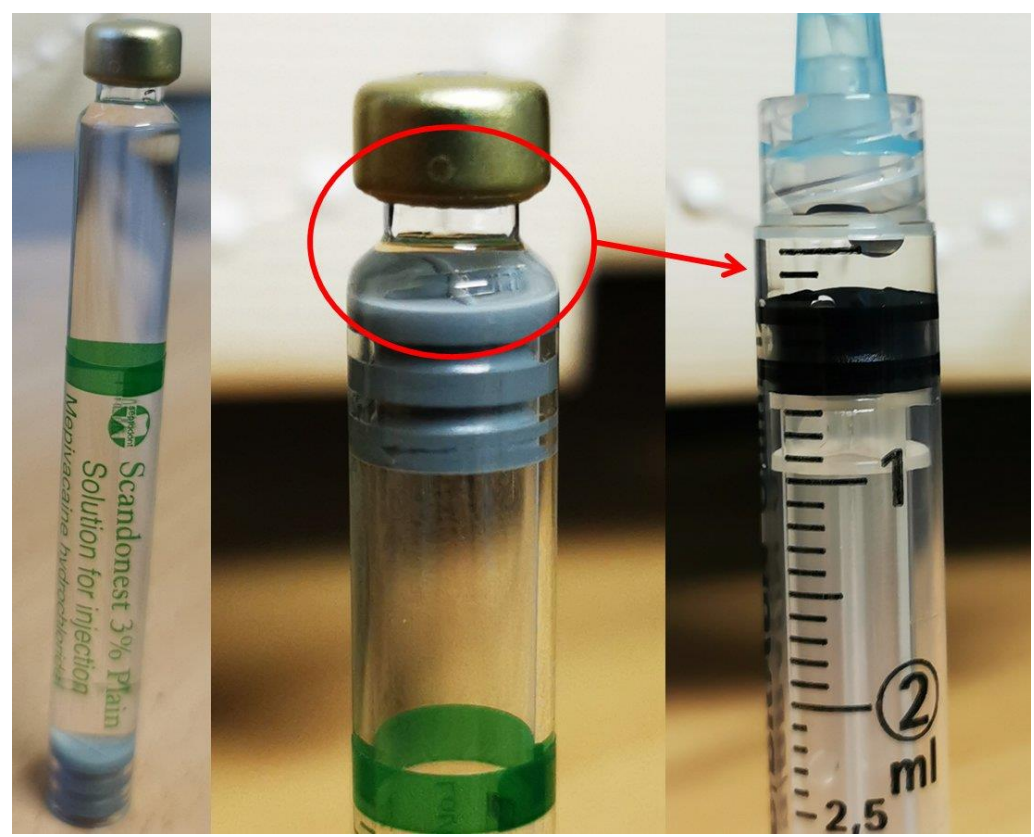

Figure 2: the last $0.2 \mathrm{ml}$ of a $2.2 \mathrm{ml}$ Scandonest cartridge extracted via a Luer syringe

The maximal adult doses for M.HCl, and the dose per body weight, vary widely from source to source for both total dose and dose by weight (see table 3), with another (unverified) internet source at $500 \mathrm{mg}$ as an MSD. In UK podiatric practice, the figures quoted above of $6 \mathrm{mg} / \mathrm{kg}$ - and an upper maximal of $400 \mathrm{mg}$ - are commonly used but often without reference, and rarely quoting an original reference (Reilly Rule 101 - always find the original source).

\begin{tabular}{|l|c|c|l|}
\hline Reference & $\begin{array}{c}\text { Dose } \\
\left(\mathbf{m g} / \mathbf{k g}^{-1}\right)\end{array}$ & $\begin{array}{c}\text { Total Dose } \\
(\mathbf{m g})\end{array}$ & Notes \\
\hline Septodont, 2013 & 4.4 & 300 & $0.15 \mathrm{ml} / \mathrm{kg}^{-1}$ \\
\hline Crawford, 2012 & 5 & 300 & $7 \mathrm{mg} / \mathrm{kg}^{-1}$ with vasoconstrictor \\
\hline University of Iowa, 2019 & $4.5-5$ & 400 & $1 \mathrm{~g} \mathrm{in} 24$ hours \\
\hline Taylor and McLeod, 2020 & 5 & Not given & $7 \mathrm{mg} / \mathrm{kg}^{-1}$ with vasoconstrictor \\
\hline Metcalfe and Reilly, 2010* & 6 & 400 & No original reference \\
\hline Malamed, 2019 & 6.6 & 400 & The same with vasoconstrictor \\
\hline Lee, 2017 & Not given & 550 & Based on FDA figure \\
\hline
\end{tabular}

Table 3: the variety of adult MSDs ( ${ }^{*}$ fails Reilly Rule 101 )

Williams and Walker (2014) note that dose limits (mg/kg-1) for local anaesthetics based on body weight are well-established (the points above should be noted), but that the calculation of the maximum safe volume $(\mathrm{ml})$ of a given agent and formulation can be complex and subject to errors. Working out the MSD can be done using various methods. 
Podiatrists commonly use the following 2-step approach (Metcalfe and Reilly, 2010):

1. drug MSD (in $\mathrm{mg} / \mathrm{kg}$ ) $\times$ patient weight (in $\mathrm{kg}$ ) = total dose (MSD in $\mathrm{mg}$ )

2. $\mathrm{MSD}($ in $\mathrm{mg})=$ volume (in $\mathrm{ml}) \times$ drug percentage $($ as $\mathrm{w} / \mathrm{v}) \times 10$

A worked example using 3\% $\mathrm{M} . \mathrm{HCl}$ for a $50 \mathrm{~kg}$ patient would be:

$$
\begin{aligned}
& \text { MSD (mg): } 50(\mathrm{~kg}) \times 6(\mathrm{mg} / \mathrm{kg}-1)=300 \mathrm{mg} \\
& 300 \mathrm{mg}=\text { unknown volume } \times 3 \% \times 10 \\
& \text { MSD (volume) }=\frac{300}{3 \times 10}=10 \mathrm{ml}
\end{aligned}
$$

An alternative method is to use the drug concentration in a one-step method (Williams and Walker, 2014):

$$
\text { maximal volume }(\mathrm{ml})=\frac{\text { body weight }(\mathrm{kg}) \text { x maximum dose }(\mathrm{mg} / \mathrm{kg})}{\text { concentration }(\mathrm{mg} / \mathrm{ml})}
$$

A worked example using 3\% $\mathrm{M} . \mathrm{HCl}$ (a 3\% solution is a $30 \mathrm{mg} / \mathrm{ml}-1$ concentration), for our $50 \mathrm{~kg}$ patient would be:

$$
\frac{50 \times 6}{30}=\mathbf{1 0 m l}
$$

The upper patient weight for drug calculations is usually considered to be $70 \mathrm{~kg}$. As Metcalfe and Reilly note: “...metabolic capacity is not increased in a linear manner with weight. Although calculations based upon body surface area would provide a more accurate measure of an appropriate dose, body weight is the normal factor against which MSDs are calculated in podiatry. As a guide, in healthy patients a maximal body weight of $70 \mathrm{~kg}$ is taken for the calculation of maximum safe dose of local anaesthetic. A person weighing $140 \mathrm{~kg}$ does not have a liver mass twice that of someone weighing $70 \mathrm{~kg}$ ". The British National Formulary (BNF, 2020) states that doses should be calculated based on ideal body weight, which for most adults is $60-75 \mathrm{~kg}$, depending on height and sex.

$\mathrm{M} . \mathrm{HCl}$ use in children is worthy of special note. Various formulas exist to calculate dosing in infants and children. Clark's rule equation is defined as the weight of the patient in pounds divided by the average standard weight of $150 \mathrm{lb}$ multiplied by the adult dose of a drug to equal the paediatric medication dose (Delgado et al, 2020). Using the two-step, worked example above for our $50 \mathrm{~kg}$ patient (110lbs), this would be:

$$
\begin{aligned}
& \left(\frac{110}{150}\right) \times 400=293 \mathrm{mg} \\
& 293 \mathrm{mg}=? \text { volume } \times 3 \% \times 10 \\
& \text { MSD (volume) }=\frac{293}{3 \times 10}=\mathbf{9 . 7} \mathbf{m l}
\end{aligned}
$$

Young's rule, based on the age of the child, is (Wade and Martinez, 2020):

adult dose $x($ age $\div($ age +12$))=$ child's dose

For our $50 \mathrm{~kg}$ patient who is 14 years old, this would be: 
$400 \times(14 \div(14+12)=215 \mathrm{mg}$

$213 \mathrm{mg}=$ ? volume $\times 3 \% \times 10$

$\operatorname{MSD}($ volume $)=\frac{215}{3 \times 10}=7.2 \mathrm{ml}$

Septodont (2013) recommended that "the quantity to be injected should be determined by the age and weight of the child and the magnitude of the operation. The average dosage is $0.75 \mathrm{mg} / \mathrm{kg}=0.025 \mathrm{ml}$ of mepivacaine solution per $\mathrm{kg}$ body weight. Maximum recommended dosage: do not exceed the equivalent of $3 \mathrm{mg}$ mepivacaine $/ \mathrm{kg}(0.1 \mathrm{ml}$ mepivacaine $/ \mathrm{kg})$ of body weight." They caution against use in children below 4 years of age (i.e. weighing at least $20 \mathrm{~kg}$ ). Note that this is half of the oft-quoted adult dose. One must also remember the physiological discrepancy between a would-be prop forward 10-year-old and a 15-year-old that needs to run around in the shower to get wet.

The College of Podiatry Nail Surgery guidelines (Gohil, 2019) quote an earlier statement from the then Director of Education, Ashcroft in 2003 and notes that M.HCl is not licenced for podiatric use in children because the manufactures did not apply for such a licence. Ashcroft went on to reassure members that "The Society would consider the administration of Scandonest, suitably dose adjusted for children, to be acceptable professional practice."

\section{Discussion}

A brief overview of LA theory has been presented together with a more detail update on the drug mepivacaine. It was surprising to see the discrepancies in the literature over the various chemo-physical properties of the drug, as well as variability is MSD values. This cuts across the traditional way LA theory is taught in UK podiatric practice.

Malamed (2019) - in a key dental anaesthetic text - suggests that the properties of an LA include:

- It should not be irritating to the tissue to which it is applied

- It should not cause any permanent alteration of nerve structure

- Its systemic toxicity should be low

- It must be effective regardless of whether it is injected into the tissue or is applied topically to mucous membranes

- The time of onset of anaesthesia should be as short as possible

- The duration of action must be long enough to permit completion of the procedure yet not so long as to require an extended recovery

The choice of LA in peripheral nerve blockade is (or should be) determined by desired speed of onset, block intensity, and duration of anaesthesia and analgesia (Eng, 2014) and therefore Podiatrists should consider the use other agents where indicated (Uddin and Reilly, 2008). It might be argued that this is less important for the humble digital block and therefore in this, $3 \% \mathrm{M}, \mathrm{HCl}$ is a good choice.

One of the factors affecting the duration of peripheral nerve block is the total dose of LA: dose being the product of volume and concentration (Fenten et al, 2015). Their study used $1 \%$ and $1.5 \%$ mepivacaine preparations. Gordon et al., (1960) used M.HCl on 230 humans as a $2 \%$ concentration for peripheral nerve blockade and favoured it over procaine and lidocaine for its quicker onset and duration (3-4 times longer), demonstrating satisfactory and prolonged anaesthesia without the addition of vasoconstrictors. No patients recorded toxic manifestations or tissue irritation in this study. 
Maher et al (2008) note that the Department of Health (DoH) expressed concerns regarding the non-medical administration of local anaesthetics when access for first granted and placed restrictions on the maximum dosage which could be administered in a 24-hour period. They go on to summarise earlier papers that state the Society of Chiropodists successfully fought against this restriction and in 1980 the restriction was lifted by the $\mathrm{DoH}$, allowing podiatrists to use their clinical judgement in deciding dose. Note that the 24-hour restriction still pervades in the Podiatric lexicon (in many, readily searchable Podiatry Department protocols) some 40 years later without consideration of the true halflife of a given drug: 1-2 hours for $\mathrm{M} . \mathrm{HCl}$. In fact, continuous infusion is common with anaesthetic practice for post-operative pain control. Buettner et al (1989) report on catheter-induced axillary plexus blocks performed in 17 patients using $400 \mathrm{mg}$ of M.HCl every two hours. One patient had 12 injections of 400mg of mepivacaine in 24 hours - an overall dosage of $4800 \mathrm{mg}$ - without evident signs of central nervous system or cardiovascular toxicity. Most LAs will not produce CV toxicity until the blood concentration exceeds three times that necessary to produce seizures.

Rosenberg et al (2004) suggest that MSD calculations referring to the total amount of the drug per body mass of the patient do not account for the site of administration and advocated abandoning blanket maximum doses in favour of a therapeutic range. They emphasized the importance of variables such as age, site and speed of injection, and the presence of systemic disease (especially hepatic, renal, and cardiac disease). Butterworth (2017) notes that there is no scientific justification for the exact dose recommendations or the $\mathrm{mg} / \mathrm{kg}$ MSD guideline, and that any recommendation on the MSD can be valid only in reference to a specific nerve block procedure. Instead, he advocates more a clinically adequate 'safe dose range'. Moore et al., (1997), for example, conducted a trial on humans using up to $500 \mathrm{mg}$ of $\mathrm{M} . \mathrm{HCl}$ with no clinically significant outcome of systemic toxicity regardless of age, gender and weight. In contrast, Reynolds (2005), while supporting variation based on individual patient factors, still recognized the importance of imposing clear limits.

Rosenberg et al (2004) stated that MSD recommendations are published by the manufacturer giving a false assumption that the manufacturers are responsible for the guideline. However, as per direct communication with the CEO of IBM Watsons international pharmaceutical industry, this is not the case and the guidelines can be traced to their original source being transcriptions from medical professionals. This is not clearly stated upon distribution and raises further debate for MSD recommendations being evidence based. De Luke et al (2018) highlighted the discrepancy in recommendations for maximum doses and in the teaching of safe maximum doses in dental schools with key texts and manufacturer guidelines giving different figures. They concluded that students should be made aware that there is more than one standard, and that teaching should emphasize sound medical and pharmacologic principles, a concern echoed in this paper. The order of peak plasma concentration after a single dose is: intrapleural $>$ intercostal $>$ lumbar epidural $>$ brachial plexus $>$ subcutaneous $>$ sciatic $>$ femoral. (Taylor and McLeod, 2019). The implication from the literature is that pedal blocks - being even more distal - have slower systemic uptake and reduced potential for acute overdosage.

There are currently no studies suggesting a safe prediction of toxicity of LA in humans (Kihm, 2004) and mepivacaine toxicity is rarely reported, (Luduena, 1960; Manassero, et al, 2014) however, it is important to understand the properties, mode of action and clinical signs of toxicity. When administered simultaneously, mepivacaine and bupivacaine interact synergistically to produce a higher-than-expected free concentration of mepivacaine. This interaction increases the risk of toxicity (Hartrick, 1984). Saraghi et al., (2015) provided data specific to LA systemic toxicity (LAST) in children. They compared LA agents and found that using $\mathrm{M} . \mathrm{HCl} 3 \%$ plain solution it is easier to exceed the 
recommended MSD due to its potency. Inclusively, they mention Clark's rule and the Rule of 25 to calculate the MSD in children.

For all the variability in dose calculations, Malamed (2019) states that "local anaesthetics are the safest and the most effective drugs available in all of medicine for the prevention and the management of pain" with the added proviso "when used properly". Koay (2002) also feels that when used properly, LA agents are very effective at producing a transient regional loss of sensation with minimal risks of adverse effects. $\mathrm{M} . \mathrm{HCl}$ remains the most popular choice amongst UK podiatrists for nail surgery and will likely remain so. M.HCl's 3\% presentation makes for a potent and popular LA agent but whose use in UK Podiatry has been largely confined to digital blocks, though some Podiatrists and Podiatric Surgeons have utilised $\mathrm{M} . \mathrm{HCl}$ for a wider variety of foot and ankle pathology and diagnostic investigative purposes (Maher et al ,2008).

\section{Conclusions}

In the UK, the podiatric LA drug of choice is mepivacaine hydrochloride. It is a good choice for digital anaesthesia, and its use has transformed the treatment of nail pathology. It is almost equally popular in Dentistry but less so in the world of (medical) anaesthesia where less cardio-toxic agents such as levo-bupivacaine and ropivacaine are the first line agents for peripheral nerve block because of their reduced cardiotoxicity. The effectiveness of a given LA is influenced by the dose, site of administration, additives, temperature, and changes in neural susceptibility: something not emphasised in Podiatric education. A rigid MSD calculation without consideration of patient factors is therefore open to critique and made more difficult by the variability of maximal dosage presented in the literature, and differing calculations available to estimate the same.

Author Contributions: IR conceived the aim and format of the paper. NB performed the literature search and produced the first draft. All authors made substantial contributions to the final version.

Funding: This research received no external funding.

Institutional Review Board Statement: Ethical review and approval were waived for this study as the study did not involve humans or animals.

Acknowledgments: We wish to thank Jackie Locke, (Lecturer at the Glasgow Caledonian School of Podiatry), George Flanagan (Consultant Podiatric Surgeon) for figure 2, and Anthony Maher/Mark Price (Consultant Podiatric Surgeons) and Prof Alan Borthwick (Southampton University) for their help with the format and scope of this article.

Conflicts of Interest: The authors declare no conflict of interest.

\section{References}

Af Ekenstam, B. A., Egner, B., Ulfendahl, L. R., Dhungr, K. G., \& Oljelund, O. (1956). Trials with Carbocaine: a new local anaesthetic drug. British Journal of Anaesthesia, 28(11), 503-506. https://doi.org/10.1093/bja/28.11.503.

Af Ekenstam, B., Egner, B. Ö. R. J. E., \& Pettersson, G. Ö. S. T. A. (1957). Local anaesthetics: I. N-alkyl pyrrolidine and $\mathrm{N}$-alkyl piperidine carboxylic acid amides. Acta Chem Scand, 11, 1183-90. Available from: http://actachemscand.org/pdf/acta vol 11 p1183-1190.pdf. Accessed 19.11.20.

Becker, D. E., \& Reed, K. L. (2006). Essentials of local anesthetic pharmacology. Anesthesia Progress, 53(3), 98-109. https://doi.org/10.2344/0003-3006(2006)53[98:EOLAP]2.0.CO;2

Becker, D. E., \& Reed, K. L. (2012). Local anesthetics: review of pharmacological considerations. Anesthesia Progress, 59(2), 90-102. https://doi.org/10.2344/0003-3006-59.2.90. 
Borthwick, A. M. (2001). Occupational imperialism at work: the case of podiatric surgery. British Journal of Podiatry, 4(3) 70-79. Available from: https://eprints.soton.ac.uk/17810/.

Borthwick, A. M. (2005). 'In the Beginning': local anaesthesia and the Croydon postgraduate group. British Journal of Podiatry, 8(3), 87-101. Available from: https://eprints.soton.ac.uk/17804/.

Broomhead, C. (2020). Local Anaesthetics in Neale's Disorders of the Foot and Ankle E-Book, 435-446. Elsevier. https://www.elsevier.com/books/neales-disorders-of-the-foot-and-ankle/burrow/978-0-7020-6223-0.

Brockmann, W. G. (2014). Mepivacaine: a closer look at its properties and current utility. Gen Dent, 62(6), 70-5. Available from: https://www.agd.org/docs/default-source/default-document-library/nd14 gendent.pdf?sfvrsn=0\#page=72. Accessed 20.11.20.

Buettner, J., Hoppe, U., Klose, R., \& Wresch, P. (1989). Serum levels of mepivacaine-HCl during continuous axillary brachial plexus block. Regional Anesthesia: The Journal of Neural Blockade in Obstetrics, Surgery, E Pain Control, 14(3), 124-127. https:/pubmed.ncbi.nlm.nih.gov/2486591/.

Butterworth, J. IV. (2017). Clinical Pharmacology of Local Anesthetics in Hadzic's Textbook of Regional Anesthesia and Acute Pain Management, Second Edition e-book. McGraw-Hill Education - Europe. ISBN: 978-0-07-174122-4.

Calatayud, J., \& González, Á. (2003). History of the development and evolution of local anesthesia since the coca leaf. Anesthesiology, 98(6), 1503-1508. https://doi.org/10.1097/00000542-200306000-00031.

Columb, M. O., \& MacLennan, K. (2007). Local anaesthetic agents. Anaesthesia and Intensive Care Medicine, 8(4), 159-162. https://doi.org/10.1016/j.mpaic.2007.01.007.

Chuan, A., \& Harrop-Griffiths, W. (2017). Hadzic, A. (ed) The History of Local Anesthesia in Hadzic's Textbook of Regional Anesthesia and Acute Pain Management, 2nd ed e-book. McGraw-Hill Education - Europe. ISBN: 978-0-07174122-4.

Crawford, M. E. (2012). Dockery, G. D., \& Crawford, M. E. (eds) Anesthesia in Lower Extremity Soft Tissue E Cutaneous Plastic Surgery, 2nd ed. Elsevier Health Sciences. ISBN: 978-0-7020-3136-6.

De Jong, R. H. (1994). Local anesthetics: from cocaine to xylocaine. Local Anesthetics, Mosby Yearbook, St. Louis, 1-8.

Delgado, B.J., Safadi, A.O., Bajaj, T. (2020). Clark's Rule. [Updated 2020 Aug 26]. In: StatPearls [Internet]. Treasure Island (FL): StatPearls Publishing. Available from: https://www.ncbi.nlm.nih.gov/books/NBK541104/. Accessed 20.11.20.

DeLuke, D. M., Cannon, D., Carrico, C., Byrne, B. E., \& Laskin, D. M. (2018). Is Maximal Dosage for Local Anesthetics Taught Consistently Across U.S. Dental Schools? A National Survey. Journal of Dental Education, 82(6), 621-624. https://doi.org/10.21815/jde.018.071.

Diaz, P. M. (1975). Allergy to procaine and mepivacaine. JAMA, 231(4), $347-347$. https://doi:10.1001/jama.1975.03240160013014.

Eng, H. C., Ghosh, S. M., \& Chin, K. J. (2014). Practical use of local anesthetics in regional anesthesia. Current Opinion in Anaesthesiology, 27(4), 382-387. https://doi.org/10.1097/ACO.0000000000000091.

Estrada, J. L., Perez-Laiz, J. L., Latasa, M., \& Rodriguez-Paredes, A. (2011). Immediate allergy to mepivacaine. Journal of Investigational Allergology $\mathcal{E} \quad$ Clinical Immunology,21(6), $492 . \quad$ Available from: https://pubmed.ncbi.nlm.nih.gov/21995186/. Accessed 19.11.20.

Falace, D. A., \& Hill, J. S. (1985). Allergy to lidocaine and mepivacaine: report of a case. The Compendium of Continuing Education in Dentistry, 6(4), 280-282. Available from: https://europepmc.org/article/med/3858047. Accessed 19.11.20.

Fenten, M. G. E., Schoenmakers, K. P. W., Heesterbeek, P. J. C., Scheffer, G. J., \& Stienstra, R. (2015). Effect of local anesthetic concentration, dose and volume on the duration of single-injection ultrasound-guided axillary brachial plexus block with mepivacaine: A randomized controlled trial. BMC Anesthesiology, 15(1), 1-8. https://doi.org/10.1186/s12871-015-0110-0. 
Gohil, K. (2019). Nail Surgery Guidelines. College of Podiatry. Available from: www.feetforlife.org. Accessed 19.11.20. Gonzalez-Delgado, P., Anton, R., Soriano, V., Zapater, P., \& Niveiro, E. (2006). Cross-reactivity among amide-type local anesthetics in a case of allergy to mepivacaine. Journal of Investigational Allergology and Clinical Immunology, 16(5), 311. Available from: http://www.esmonformacion.com/jiaci/issues/vol16issue05/8.pdf. Accessed 19.11.20.

Gordon, R. A., Kerr, J. H., \& Taylor, R. (1960). A laboratory and clinical evaluation of mepivacaine (Carbocaine®). Canadian Anaesthetists' Society Journal, 7(3), 290-296. https://doi.org/10.1007/BF03028159.

Hartrick, C. T., Dirkes, W. E., Coyle, D. E., Raj, P. P., \& Denson, D. D. (1984). Influence of bupivacaine on mepivacaine protein binding. Clinical Pharmacology \& Therapeutics, 36(4), 546-550. https://doi.org/10.1038/clpt.1984.217.

Hiyoshi, K., Iwanaga, Y., Kado, K., \& Takeda, K. (1978). Allergic reactions caused by mepivacaine (author's transl). Masui. The Japanese Journal of Anesthesiology, 27(2), 177. https://pubmed.ncbi.nlm.nih.gov/633623/.

Hodgkins, A. L., \& Huxley, A. F. (1952). J Physiol, 117(4), 500-544. Available from: https://www.ncbi.nlm.nih.gov/pmc/articles/PMC1392413/pdf/jphysiol01442-0106.pdf. Accessed 19.11.20.

Khan, K. H. (2017). Local anaesthetic techniques. Podiatry Management. March, 151-163. Available from: https://www.podiatrym.com/cme/CME317.pdf. Accessed 19.11.20.

Kihm, C. A. (2011). Local Anesthetic Considerations in Podiatric Surgery. Podiatry Institute, 95(43), 231-235. Available from: http://www.podiatryinstitute.com/pdfs/Update 2011/2011 43.pdf. Accessed 19.11.20.

Koay, J., \& Orengo, I. (2002). Application of local anesthetics in dermatologic surgery. Dermatologic surgery, 28(2), 143148. https://doi.org/10.1046/j.1524-4725.2002.0112.x.

Lee, J. M., \& Shin, T. J. (2017). Use of local anesthetics for dental treatment during pregnancy; safety for parturient. Journal of Dental Anesthesia and Pain Pedicine, 17(2), 81-90. https://doi.org/10.17245/jdapm.2017.17.2.81.

López, M., Calvo, M., Sancho, A., Brogly, N., Guasch, E., \& Gilsanz, F. (2017). Effective volumes of 1.5\% mepivacaine with different sodium concentration for ultrasound guided popliteal block. Journal of Clinical Anesthesia, 37, 139-144. https://doi.org/10.1016/j.jclinane.2016.12.009.

Luduena, F. P., Hoppe, J. O., Coulston, F., \& Drobeck, H. P. (1960). The pharmacology and toxicology of mepivacaine, a new local anesthetic. Toxicology and Applied Pharmacology, 2(3), 295-315. https://doi.org/10.1016/0041$\underline{008 X(60) 90059-4 .}$.

Maher, A. J., Metcalfe, S. A., \& Parr, S. (2008). Local anaesthetic toxicity. The Foot, 18(4), 192-197. https://doi.org/10.1016/j.foot.2008.05.002.

Maher, A. J., (2020). Personal communication.

Malamed, S. F. (2019). Neurophysiology in Handbook of Local Anesthesia-E-Book. 9th ed. Elsevier Health Sciences. https://www.elsevier.com/books/handbook-of-local-anesthesia/malamed/978-0-323-58207-0.

Manassero, A., Bossolasco, M., Ugues, S., \& Bailo, C. (2014). An atypical case of two instances of mepivacaine toxicity. Journal of Anaesthesiology, Clinical Pharmacology, 30(4), 582-583. https://doi.org/10.4103/0970-9185.142887.

Meffin, P., Long, G. J., \& Thomas, J. (1973). Clearance and metabolism of mepivacaine in the human neonate. Clinical Pharmacology \& Therapeutics, 14(2), 218-225. https://doi.org/10.1002/cpt1973142218.

Merriam-Webster. (n.d.). (2020). Maximum dose. In Merriam-Webster.com medical dictionary. Available at https://www.merriam-webster.com/medical/maximum\%20dose. Accessed 19.11.20.

Metcalfe, S., Reilly, I. N. (2010). Local Anaesthetics in Foot and Ankle Injection Techniques. A Practical Guide. Elsevier Churchill Livingstone. ISBN: 9780702031076.

Moore, D. C., Bridenbaugh, L. D., Thompson, G. E., Balfour, R. I., \& Horton, W. G. (1977). Factors determining dosages of amide-type local anesthetic drugs. Anesthesiology: The Journal of the American Society of Anesthesiologists, 47(3), 263268. https://doi.org/10.1097/00000542-197709000-00006. 
Multrum, C. (2020). Mepivacaine. Available from: https://www.drugs.com/mtm/mepivacaine.html. Accessed 19.11.20.

Pope, R. L., \& Brown, A. M. (2020). A primer on tissue pH and local anesthetic potency. Advances in Physiology Education, 44(3), 305-308. https://doi.org/10.1152/advan.00018.2020.

Pirahanchi, Y., Jessu, R., \& Aeddula, N.R. (2020). Physiology, Sodium Potassium Pump. [Updated 2020 Aug 22]. In: StatPearls [Internet]. Treasure Island (FL): StatPearls Publishing. Available from: https://www.ncbi.nlm.nih.gov/books/NBK537088/. Accessed 19.11.20.

Reynolds, F. (2005). Maximum recommended doses of local anesthetics: a constant cause of confusion. Regional Anesthesia and Pain Medicine, 30(3), 314. https://doi:10.1016/j.rapm.2005.01.006.

Rosenberg, P. H., Veering, B. T., \& Urmey, W. F. (2004). Maximum recommended doses of local anesthetics: A multifactorial concept. Regional Anesthesia and Pain Medicine, 29(6), 564-575. https://doi.org/10.1016/j.rapm.2004.08.003.

Saraghi, M., Moore, P. A., \& Hersh, E. V. (2015). Local anesthetic calculations: Avoiding trouble with pediatric patients. General Dentistry, 63(1), 48-52. https://pubmed.ncbi.nlm.nih.gov/25574719/.

Septodont. (2009). Mepivacaine HCl. Available from: https://www.septodont.in/sites/default/files/Scandonest.pdf. Accessed 19.11.20.

Septodont.

(2013).

Septodont

pain

control.

Available

at

https://www.septodontlearning.co.uk/flipbook/pain control/files/basic-html/page38.html. Accessed 19.11.20.

Sharma, V., Harper, N. J. N., Garcez, T., \& Arkwright, P. D. (2013). Allergic reaction to mepivacaine in a child. British Journal of Anaesthesia, 110(6), 1059-1060. https://doi.org/10.1093/bja/aet147.

Statutory Instruments. (2012). The Human Medicines Regulations 2012. No. 1916. London: The Stationery Office. Schedule 17, Part 3 - Exemptions from the restriction on administration of prescription only medicines. Available from: https://www.legislation.gov.uk/uksi/2012/1916/schedule/17/made. Accessed 19.11.20.

Taylor, A., \& McLeod, G. (2019). Basic pharmacology of local anaesthetics. BJA Education, $20(2)$, 34-41. https://doi.org/10.1016/j.bjae.2019.10.002.

Taylor, A., \& McLeod, G. (2020). Corrigendum to 'Basic pharmacology of local anaesthetics'[BJA Education 20 (2020) 34-41]. BJA Education, 20(4), 140. https://doi.org/10.1016/j.bjae.2020.02.001.

Torbay and South Devon NHS Foundation Trust. (2017) Podiatry Nail Surgery - Clinical Guidelines. Ref No: 1682 Version 2. Available from: http://documents.torbayandsouthdevon.nhs.uk/TSDFT/G1682.pdf?web=1. Accessed 19.11.20.

Tsuchiya, H., Mizogami, M., Ueno, T., \& Takakura, K. (2007). Interaction of local anaesthetics with lipid membranes under inflammatory acidic conditions. Inflammopharmacology, 15(4), 164-170. https://doi.org/10.1007/s10787-007$\underline{1601-5}$.

Uddin, A., \& Reilly, I. (2008) Ropivacaine and levobupivacaine: Potential uses in podiatric medicine and surgery. Podiatry Now, 11(4), 22-28. Available from: www.feetforlife.org. Accessed 19.11.20.

University of Iowa. (2019). Iowa Head and Neck Protocols: Maximum recommended doses and duration of local anesthetics.

Available from: https://medicine.uiowa.edu/iowaprotocols/maximum-recommended-doses-and-duration-localanesthetics. Accessed 19.11.20.

Venemalm, L., Degerbeck, F., \& Smith, W. (2008). IgE-mediated reaction to mepivacaine. Journal of Allergy and Clinical Immunology, 121(4), 1058. https://doi:10.1016/j.jaci.2007.12.1154.

Wade, C. I., Martinez, T. (2020). Young's Rule. [Updated 2020 Apr 20]. In: StatPearls [Internet]. Treasure Island (FL): StatPearls Publishing; 2020 Jan. Available from: https://www.ncbi.nlm.nih.gov/books/NBK554603/.

Williams, D. J., \& Walker, J. D. (2014). A nomogram for calculating the maximum dose of local anaesthetic. Anaesthesia, 69(8), 847-853. https://doi.org/10.1111/anae.12679. 